group 2 received transfusion in the first 3 days of life $(\mathrm{p}=$ 0.384). The number and volume of PRBC transfusions were similar in both groups (Table 1). Comparison of laboratory outcomes resulted in statistically significance only in median $\mathrm{Hb}$ values at first $(16.8 \mathrm{~g} / \mathrm{dL}$ [range, 14.1 to $18.8 \mathrm{~g} / \mathrm{dL}$ ] and $15.4 \mathrm{~g} /$ $\mathrm{dL}$ [range, 12.3 to $18.5 \mathrm{~g} / \mathrm{dL}$ ]; $\mathrm{p}=0.019$ ) and 24th hour after birth $(16.1 \mathrm{~g} / \mathrm{dL}$ [range, 13.4 to $21 \mathrm{~g} / \mathrm{dL}$ ] and $14.9 \mathrm{~g} / \mathrm{dL}$ [range, 10.2 to $18 \mathrm{~g} / \mathrm{dL}$ ]; $\mathrm{p}=0.021$ ) between UCM and control groups, respectively. Phlebotomy volume was found as a statistically significant risk factor for the need for PRBC transfusion ( $p$ $=0.005$ ).

Conclusions UCM in delivery room results in a higher Hb level in the first day of life. In these groups of infants, phlebotomy losses may impact the transfusion need.

\section{P0-0612 AN UNEXPECTED DIGIT DILEMMA - A CASE OF MIRROR IMAGE DUPLICATION OF BOTH HANDS AND FEET}

${ }^{1}$ A Baines, ${ }^{1} \mathrm{~J}$ Clegg, ${ }^{1} Y$ Kumar, ${ }^{2}$ B Castle. ${ }^{1}$ Neonatal Department, Royal Cornwall Hospital Trust, Truro, UK; ${ }^{2}$ Clinical Genetics, Royal Devon and Exeter Hospital, Exeter, UK

\subsection{6/archdischild-2014-307384.1254}

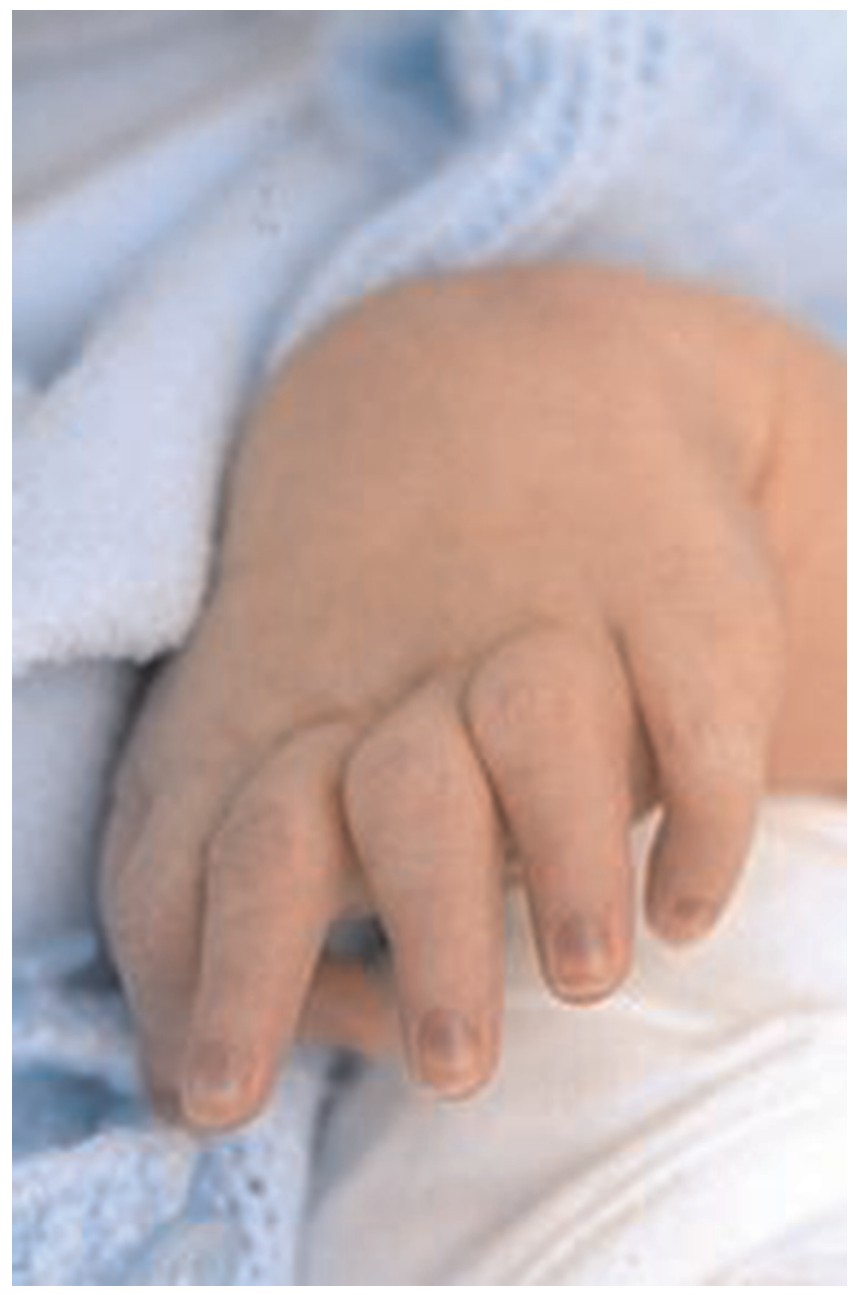

Abstract P0-0612 Figure 1

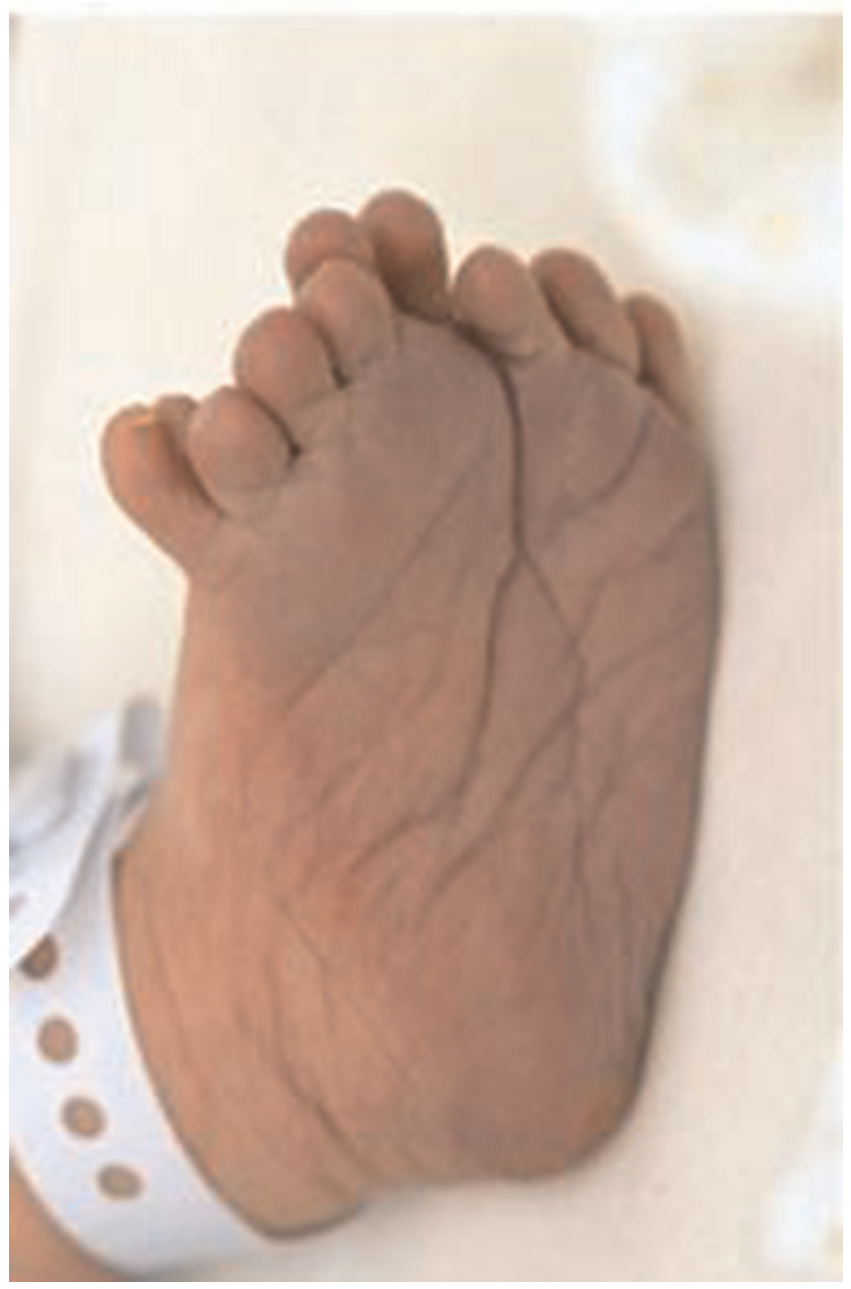

Abstract P0-0612 Figure 2

Background We present a case characteristic of Laurin-Sandrow syndrome in a term male infant. The infant is the third son of Caucasian parents born following uncomplicated pregnancy. There is no family history of limb abnormalities or genetic conditions.

The infant was noted to have a wide nasal bridge, bilateral erythematous linear prominences on his columella with polydactyly and syndactyly of both hands and feet. There was wrist flexion and cupped hands, each with 7 normal length digits but no opposable thumbs. The feet were of 'mirrored' appearance with a further 17 digits.

Methods MRI imaging of the brain revealed overall structural brain asymmetry, with agenesis of the corpus callosum and ventricular dilatation. Metacarpals and metatarsals were present for each digit, with an additional extra-axial digit noted on the left foot. Initial suggestion of autosomal dominant Grieg Cephalopolysyndactly (GCP) was revised by the Clinical Geneticist to Laurin-Sandrow Syndrome, with genetic PCR negative for GCP.

Results Laurin-Sandrow Syndrome represents an extremely rare genetic condition of polysyndactyly associated with 14 q13 gene translocation, with fewer than 30 cases described in the literature.

Conclusion In cases of extreme duplication of digits with nasal anomalies, cranial imaging and early review by a geneticist may be key in revealing the underlying diagnosis. 